\title{
Ajuste de modelo para quantificar o efeito de plantas daninhas e época de semeadura no rendimento de soja ${ }^{(1)}$
}

\author{
Mauro Antônio Rizzardi(2), Nilson Gilberto Fleck ${ }^{(3)}$, João Riboldi(4) e Dirceu Agostinetto( ${ }^{(3)}$
}

\begin{abstract}
Resumo - O objetivo deste trabalho foi ajustar e validar um modelo matemático baseado em densidades de picão-preto (Bidens spp.) e de guanxuma (Sida rhombifolia L.), integrando a época de semeadura da soja após a dessecação da cobertura vegetal, para quantificar perdas de rendimento de grãos. Foram conduzidos quatro experimentos, em Passo Fundo e Eldorado do Sul. Os tratamentos constaram de densidades de picão-preto ou de guanxuma e de épocas de semeadura da soja em relação à data de dessecação da cobertura vegetal. Nos experimentos com picão-preto, a semeadura da soja foi realizada 3, 7 e 11 dias após dessecação (DAD) da cobertura vegetal, nos dois locais. Com infestação de guanxuma, a semeadura da soja foi realizada 3, 7 e 11 DAD em Passo Fundo, e 20, 24 e 28 DAD em Eldorado do Sul. Os dados foram analisados pelo modelo da hipérbole retangular, o qual incorpora a densidade da planta daninha e a época de sua emergência em relação à cultura. $\mathrm{O}$ atraso na semeadura da soja em relação à dessecação da cobertura vegetal aumenta os níveis de perdas de rendimento da cultura em decorrência da interferência de guanxuma e, principalmente, de picão-preto. O modelo pode ser usado para previsão das perdas de rendimento de grãos de soja causadas pelas duas espécies de plantas daninhas.
\end{abstract}

Termos para indexação: picão-preto, guaxuma, densidade de plantas daninhas, perda de rendimento, modelo matemático, dessecação de cobertura vegetal.

\section{Adjustment of model to quantify the effect of weeds and sowing time on soybean yield}

\begin{abstract}
The objective of this work was to adjust and validate a mathematical model based beggarticks (Bidens spp.) and arrowleaf sida (Sida rhombifolia L.) densities, integrating the soybean seeding time after plant cover desiccation as a variable in order to quantify the losses in grain yield. Four experiments were conducted in Passo Fundo and Eldorado do Sul, RS, Brazil. Treatments consisted of beggarticks and arrowleaf sida densities, and soybean seeding times in relation to plant cover desiccation date. In the trials performed with beggarticks, soybean seeding was carried 3, 7, and 11 days after desiccation (DAD) of plant cover, in both locations. In the trials that included arrow leaf sida, soybean seeding was performed 3, 7, and 11 DAD in Passo Fundo, and 20, 24, and 28 DAD in Eldorado do Sul. In order to analyse the data, it was used the rectangular hyperbolic model, which incorporates weed density and its emergence time in relation to the crop. Delaying soybean seeding in relation to plant cover desiccation increased the levels of crop grain yield losses due to weed interference, mainly for beggarticks. The rectangular hyperbolic model can be used to predict soybean grain yield losses for both weed species.
\end{abstract}

Index terms: beggarticks, arrowleaf sida, weed density, crop yield losses, mathematical models, plant cover desiccation.

\footnotetext{
(1) Aceito para publicação em 27 de agosto de 2002.

(2) Universidade de Passo Fundo, Fac. de Agronomia e Medicina Veterinária, Caixa Postal 711, CEP 99001-970 Passo Fundo, RS. E-mail: rizzardi@upf.tche.br

(3) Universidade Federal do Rio Grande do Sul (UFRGS), Fac. de Agronomia, Caixa Postal 776, CEP 91501-970 Porto Alegre, RS. E-mail: fleck@vortex.ufrgs.br, dirceua@vortex.ufrgs.br

(4) UFRGS, Instituto de Matemática. E-mail: riboldi@mat.ufrgs.br
}

\section{Introdução}

Os programas de manejo integrado de plantas daninhas em culturas envolvem uma série de medidas de controle a serem adotadas de maneira integrada, geralmente incluindo herbicidas como um componente, mas não colocando dependência exclusiva neles. Um componente potencial de programas de manejo integrado é a manipulação da relação de com- 
petição entre a cultura e as plantas daninhas (Cousens \& Mokhtari, 1998).

A competição exercida pela cultura pode ser usada na redução do crescimento das plantas daninhas e aumento na mortalidade delas, diminuindo, deste modo, as perdas de rendimento (Mortensen et al., 2000). Assim, o manejo da época de semeadura da cultura, após a dessecação da cobertura vegetal, no sistema de semeadura direta, pode influenciar na competitividade em relação às plantas daninhas. $\mathrm{Na}$ medida em que se consiga estabelecer a cultura em condições mais favoráveis, ela pode assumir uma posição dominante na comunidade e suprimir o crescimento das plantas daninhas. Ao trabalharem com épocas de controle de papuã, Fleck et al. (2002) observaram que o atraso na aplicação do controle dessa planta daninha reduziu menos o rendimento de grãos da soja quando a semeadura da cultura foi realizada um dia após a aplicação de dessecante (glyphosate) sobre a cobertura vegetal, em relação à semeadura efetuada dez dias após tal prática.

As plantas daninhas não interferem com a mesma intensidade em todas as etapas de desenvolvimento da cultura (Mulugeta \& Boerboom, 2000). As fases nas quais predominam estão diretamente relacionadas com a intensidade de dano que ocasionam à cultura. Dieleman et al. (1995) constataram que plantas de Amaranthus retroflexus L. (caruru) que emergiram junto com a soja causaram maiores perdas de rendimento do que as plantas daninhas que emergiram mais tarde, em densidades similares. Resultados semelhantes foram obtidos em feijão por Chikoye et al. (1995), com Ambrosia artemisiifolia L. (losna-do-campo). A relação da época de emergência das plantas daninhas com o crescimento da cultura é fundamental na determinação dos efeitos da interferência dessas plantas na cultura (Chikoye et al., 1995; Dieleman et al., 1995, 1996; Bosnic \& Swanton, 1997a, 1997b).

Os programas para decisão do manejo de plantas daninhas freqüientemente requerem estimativas quantitativas dos seus efeitos no rendimento da cultura. Os níveis de danos usados para decidir se é necessário ou não controlar as plantas daninhas podem ser derivados de equações de regressão que quantificam as perdas de rendimento em razão do nível de infestação de plantas daninhas logo após a emergência da cultura (Kropff et al., 1992). Assim, Cousens (1985) mostrou que a relação entre perda de rendimento da cultura e densidade de plantas daninhas foi bem descrita pela equação da hipérbole retangular; porém, esse modelo é limitado, uma vez que, em sua concepção, não foi previsto balancear o efeito da época de emergência das plantas daninhas em relação à cultura na intensidade de interferência que causam (Kropff \& Spitters, 1991).

Cousens et al. (1987) propuseram um modelo hiperbólico de perda no rendimento que incluiu densidade e época relativa de emergência das plantas daninhas. Esse modelo fornece melhor descrição do relacionamento entre rendimento da cultura e população de plantas daninhas, em comparação a outros modelos (Chikoye \& Swanton, 1995; Dieleman et al., 1995; Knezevic et al., 1995). O modelo de Cousens et al. (1987) mostrou-se vantajoso sobre outros modelos testados, por superar certas restrições que geralmente impediam a aplicação dos resultados em relação a outras condições ambientais.

Assim, quando for possível ajustar o modelo de Cousens et al. (1987) a dados obtidos a partir da semeadura da cultura em áreas com plantas daninhas oriundas de diferentes épocas de emergência, poder-se-á quantificar as perdas de rendimento com apenas um ajuste que inclua épocas de estabelecimento da cultura e densidades das plantas daninhas.

O objetivo deste trabalho foi ajustar e validar um modelo matemático baseado em densidades de picão-preto e guanxuma, integrando a época de semeadura da soja após a dessecação da cobertura vegetal, para quantificar perdas de rendimento de grãos.

\section{Material e Métodos}

Dois experimentos foram realizados em 1998/1999, em Passo Fundo (ambiente 1), e outros dois em 1999/2000, em Eldorado do Sul (ambiente 2). Os experimentos foram realizados no campo, no Centro de Extensão e Pesquisa Agropecuária da Faculdade de Agronomia e Medicina Veterinária da Universidade de Passo Fundo (Cepagro-UPF) e na Estação Experimental Agronômica da Universidade Federal do Rio Grande do Sul (EEA-UFRGS), em Eldorado do Sul.

Os solos das áreas experimentais são classificados como Latossolo Vermelho distrófico típico e Argissolo Verme- 
lho distrófico típico, em Passo Fundo e Eldorado do Sul, respectivamente (Embrapa, 1999). Antes da instalação de cada experimento, as áreas foram amostradas $(0-20 \mathrm{~cm})$ para análise química e granulométrica do solo, apresentando os seguintes resultados: ambiente 1: argila, $490 \mathrm{~g} / \mathrm{kg}$; pH (em água), 5,7; P, 8,1 mg/L; K, 149 mg/L e MO, $21 \mathrm{~g} / \mathrm{kg}$; ambiente 2: argila, $380 \mathrm{~g} / \mathrm{kg} ; \mathrm{pH}$ (em água), 4,8; , $2 \mathrm{mg} / \mathrm{L} ; \mathrm{K}, 116 \mathrm{mg} / \mathrm{L}$ e $\mathrm{MO}, 20 \mathrm{~g} / \mathrm{kg}$.

$\mathrm{O}$ delineamento experimental utilizado nos quatro experimentos foi completamente casualizado, disposto em esquema fatorial, sem repetições. Nos dois ambientes, os tratamentos constaram de densidades de picão-preto (Bidens pilosa L. e B. sulbalternans DC., em infestações mistas), ou de guanxuma (Sida rhombifolia L.) e de épocas de semeadura de soja em relação à última data de dessecação da cobertura vegetal.

Os experimentos foram implantados utilizando-se o sistema de semeadura direta, em áreas contendo a cobertura vegetal formada por aveia-preta (Avena strigosa Schreb.). Em todos os experimentos, o manejo da aveia foi realizado com os herbicidas glyphosate (900 g de equivalente ácido (e.a.)/ha) e 2,4-D (670 g de e.a./ha) efetuada por ocasião do florescimento das plantas de aveia-preta. Nos experimentos realizados no ambiente 1 e no experimento com picão-preto no ambiente 2 foi procedida uma segunda dessecação com paraquat (300 g/ha), para eliminar as plantas daninhas que não foram controladas com a primeira dessecação ou que emergiram no período entre a primeira e a segunda dessecação. Nesses experimentos as épocas de semeadura da soja foram estabelecidas aos 3, 7 e 11 dias após a dessecação (DAD). Na guanxuma, no ambiente 2, foi realizada somente uma dessecação, com glyphosate + 2,4-D, e a soja foi semeada 20, 24 e 28 DAD.

Aplicaram-se $300 \mathrm{~kg} / \mathrm{ha}$ da fórmula 5-20-30 e $340 \mathrm{~kg} /$ ha da fórmula 5-25-25 nos ambientes 1 e 2, respectivamente. Em ambos os experimentos, utilizou-se a cultivar de soja EMBRAPA 66, de ciclo médio e estatura média de $83 \mathrm{~cm}$, a qual foi estabelecida na densidade de $400 \mathrm{mil}$ plantas/ha, em espaçamento de $0,4 \mathrm{~m}$ entre as fileiras. No ambiente 1, a semeadura da soja foi realizada em 27 de novembro, 10 e 5 de dezembro no experimento com guanxuma e 1o, 5 e 9 de dezembro no experimento com picão-preto. No ambiente 2 , a semeadura da cultura deuse em 17,21 e 25 de novembro, no experimento com guanxuma, e em 8,12 e 16 de dezembro, no experimento com picão-preto.

As densidades de plantas daninhas foram alocadas aleatoriamente, no campo, de acordo com níveis populacionais de plantas daninhas encontrados naturalmente na área. No ambiente 1, com picão-preto, utilizaram-se 17 unidades em cada época de semeadura, cujas densidades varia- ram de 1 a 180 plantas $/ \mathrm{m}^{2}$, totalizando 51 unidades com infestação; com guanxuma foram utilizadas 15 unidades em cada época, com densidades que variaram de 1 a 60 plantas $/ \mathrm{m}^{2}$, num total de 45 unidades com infestação. No ambiente 2, com picão-preto, utilizaram-se dez unidades em cada época de semeadura, cujas densidades variaram de 1 a 110 plantas $/ \mathrm{m}^{2}$, totalizando 30 unidades com infestação; com guanxuma, foram utilizadas dez unidades em cada época, com densidades que variaram de 1 a 128 plantas $/ \mathrm{m}^{2}$, totalizando 30 unidades com infestação. Nos dois ambientes manteve-se de quatro a cinco unidades com ausência de plantas daninhas, em cada uma das épocas de semeadura da soja. Cada unidade experimental mediu $6 \mathrm{~m}^{2}(2 \times 3 \mathrm{~m})$, com cinco fileiras de soja.

O controle de plantas daninhas gramíneas nos experimentos foi feito com o herbicida graminicida clethodim (120 g/ha), acrescido do adjuvante Assist ( $0,5 \%$ volume/ volume), quando as plantas de soja apresentavam três trifólios. Durante o período experimental, foram realizadas suplementações hídricas por meio de irrigações por aspersão, para garantir adequado desenvolvimento da cultura.

As avaliações das densidades das plantas daninhas foram realizadas 20 dias após a emergência (DAE) da soja, mediante contagem dos indivíduos presentes em área de $1,0 \mathrm{~m}^{2}$ por parcela, em dois locais de cada unidade experimental.

O rendimento de grãos da soja foi determinado em $3,0 \mathrm{~m}^{2}$ $(1,2 \times 2,5 \mathrm{~m})$, englobando as três fileiras centrais da parcela. Para dados de rendimento foram calculadas as perdas porcentuais em relação às parcelas mantidas livres de plantas daninhas.

Aos dados de porcentagens de perda foi ajustado o modelo de regressão não linear da hipérbole retangular proposto por Cousens et al. (1987):

$\mathrm{P}_{\mathrm{r}}=(\mathrm{i} * \mathrm{X}) /\left(\left(\exp ^{-\mathrm{cT}}\right)+\left((\mathrm{i} / \mathrm{a})^{*} \mathrm{X}\right)\right)$;

em que: $\mathrm{P}_{\mathrm{r}}$ é a perda de rendimento (\%); $\mathrm{X}$ é a densidade de plantas daninhas; $\mathrm{T}$ é a época de semeadura da soja em relação à dessecação da cobertura vegetal preexistente na área; i é a porcentagem de perda de rendimento por unidade de planta daninha quando sua densidade por área se aproxima de zero; a é a porcentagem de perda de rendimento quando a densidade de plantas daninhas tende ao infinito; c é o parâmetro próprio do modelo.

No ajuste da equação 1, os valores de T são expressos em unidades calóricas, as quais foram calculadas utilizando-se a expressão: [(temperatura diária máxima do ar + temperatura diária mínima do ar)/2) - temperatura base]. A temperatura base usada no cálculo foi $10^{\circ} \mathrm{C}$, conforme Wiese \& Binning (1987). O valor de T integralizou os valores de unidades calóricas diárias do período da dessecação 
até a respectiva data de semeadura. Os valores integralizados de $\mathrm{T}$ foram divididos por 10 para correção da fórmula.

O ajuste do modelo da equação 1 aos dados foi realizado usando-se o procedimento Proc Nlin do programa computacional SAS (SAS Institute, 1989). Após o ajuste dos dados ao modelo de Cousens et al. (1987), fez-se comparação dos modelos ajustados entre ambientes, procedendo-se inicialmente verificação de homogeneidade de variância pelo teste de Bartlett (Gomez \& Gomez, 1984). Nos casos em que houve homocedasticidade, foi realizada a comparação entre ambientes, conforme Chow (Florez et al., 1999). Após tal procedimento, ocorrendo diferenças entre ambientes, as comparações dos parâmetros i, a e c entre ambientes foi realizada de acordo com Ratkowsky (Jasieniuck et al., 1999).

A validação dos modelos ajustados foi realizada mediante análise de correlação linear simples entre as perdas de rendimento observadas em parcelas previamente separadas para tal fim, contendo densidades variáveis de picão-preto ou guanxuma, e as perdas de rendimento estimadas pelo modelo de Cousens et al. (1987). No cálculo da perda porcentual do rendimento de grãos, utilizaram-se dados de rendimento com ausência de plantas daninhas, específicos para cada ambiente, experimento e época de semeadura. Esses valores de rendimento foram obtidos em experimentos realizados em condições similares àqueles que originaram os dados aos quais foi ajustado o modelo.

\section{Resultados e Discussão}

As perdas de rendimento de grãos da soja causadas pela presença de picão-preto variaram com a densidade da planta daninha, a época de semeadura da soja e o ambiente (Figura 1). À medida que a semeadura da soja foi atrasada, em relação à data de dessecação da cobertura vegetal, aumentaram as perdas com o incremento na densidade da planta daninha, nos dois ambientes. Os resultados confirmaram a importância dos efeitos das épocas de semeadura da cultura e da densidade da planta daninha, no rendimento da soja. Knezevic et al. (1997), também constataram que a densidade que causa redução máxima tolerada de rendimento (5\%) foi menor em plantas daninhas que germinaram mais cedo, sugerindo que a época de sua emergência em relação à cultura foi crítica em afetar o resultado da competição entre as plantas daninhas e a cultura.

O modelo de Cousens et al. (1987) permitiu a inclusão do fator época de emergência das plantas
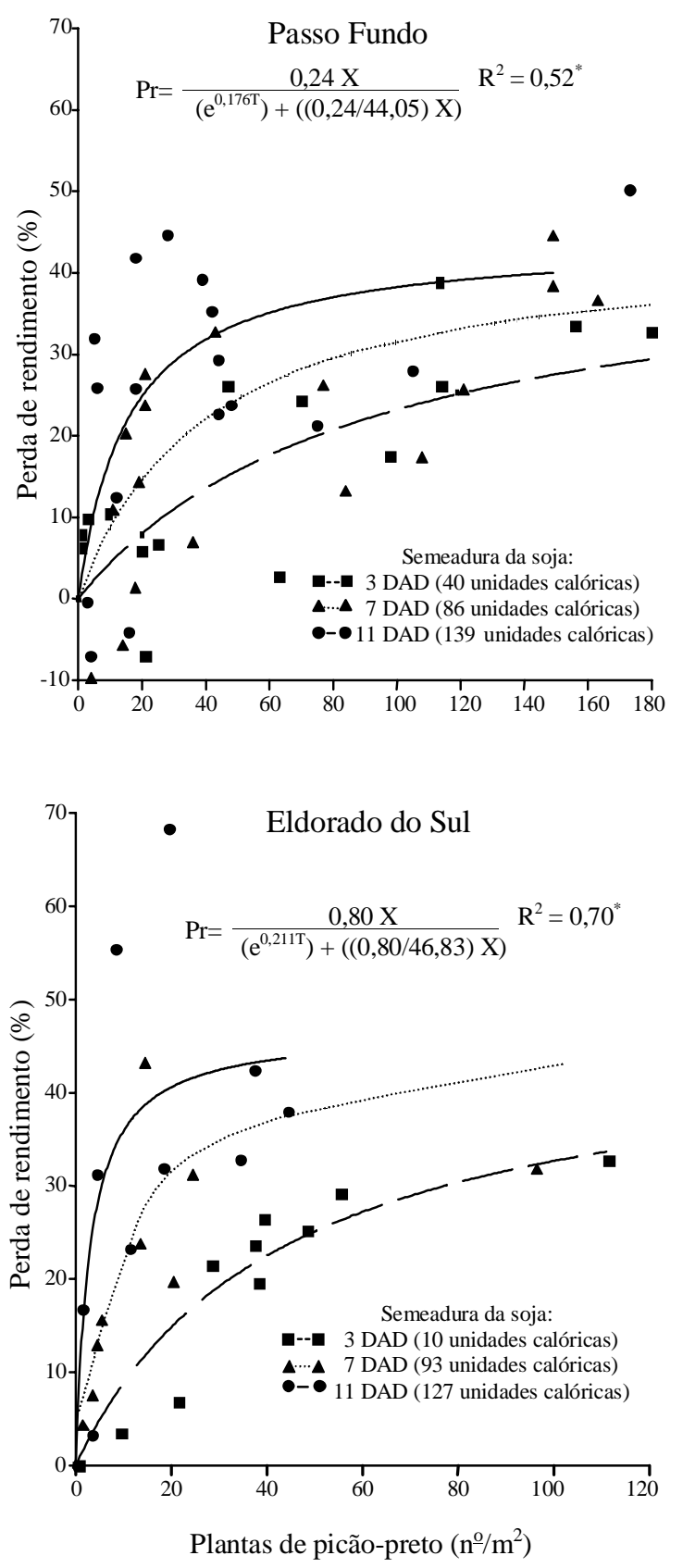

Figura 1. Perda de rendimento de grãos $\left(\mathrm{P}_{\mathrm{r}}\right)$ de soja em razão da densidade de plantas de picão-preto e da época de semeadura da soja após a dessecação (DAD: dias após dessecação) da cobertura vegetal, em Passo Fundo, RS, 1998/1999 e Eldorado do Sul, RS, 1999/2000. Nas equações de perdas de rendimento, $\mathrm{X}$ é a densidade de plantas daninhas; $\mathrm{T}$ é a época de semeadura. 
daninhas de modo a melhorar o seu ajuste. Porém, para que seu uso seja possível, são necessários dados precisos da época de emergência das plantas daninhas, em relação ao estádio de desenvolvimento da cultura, sob uma amplitude de densidades de plantas daninhas, para que se possa prever de modo confiável o resultado da competição entre plantas daninhas e a cultura (Knezevic et al., 1997). No campo, a obtenção desses dados é difícil, pois as plantas daninhas costumam emergir em fluxos discretos e sucessivos, tornando difícil ou até impossível estimar a época relativa de emergência, a fim de se aplicar o modelo que considera o efeito de ambos os fatores em razão dos fluxos de plantas daninhas (Chikoye \& Swanton, 1995). Diante disso, a substituição da emergência das plantas daninhas em relação à cultura por outros indicativos, como a época de semeadura da soja após a dessecação da cobertura vegetal, expressa em unidades calóricas, pode ser uma alternativa viável (Figura 1).

Quanto ao picão-preto, o uso do modelo baseado na densidade e na época de semeadura da soja mostrou ajuste satisfatório nos dois ambientes, e manteve a capacidade de diferenciação conforme observado pela análise individualizada de cada uma das épocas ao se aplicar o modelo de Cousens (1985) por Rizzardi (2002). Apesar de o modelo da equação 1 ser mais complexo do que o original de Cousens (1985), por incluir duas variáveis e três parâmetros, apresentou vantagem com a incorporação da época de semeadura da cultura, o que compensou sua maior complexidade.

Ainda que diferenças entre ambientes $(p<0,05)$ foram observadas em relação às perdas de rendimento de grãos decorrentes da presença de picão-preto, não se detectaram diferenças significativas entre ambientes nos parâmetros estimados. Porém, o rendimento médio da soja, na ausência de plantas daninhas, foi, aproximadamente, $25 \%$ inferior no ambiente 1 em comparação ao ambiente 2 (Tabela 1). Jasieniuck et al. (1999), ao compararem diferentes experimentos em que os parâmetros não diferiram significativamente, também constataram que as diferenças entre experimentos estão associadas aos rendimentos obtidos na ausência de plantas daninhas.
Quanto ao parâmetro i, apesar da ausência de diferença significativa entre ambientes, a estimativa foi, numericamente, em torno de 3,3 vezes maior no ambiente 2, e apresentou maior erro-padrão assintótico em relação ao ambiente 1. Conforme Dieleman et al. (1995), a ocorrência de elevado erro-padrão na estimativa do parâmetro i pode ser atribuída à variabilidade associada com experimentação de campo e à plasticidade fenotípica inerente à soja. Essa variabilidade pode dificultar a estimativa correta das perdas de rendimento em baixas densidades de plantas daninhas.

O parâmetro a, por sua vez, não diferiu entre os ambientes, tendo variado de $44 \%$ a $47 \%$, aproximadamente; porém, esses valores de perdas máximas estimadas foram inferiores às perdas verificadas no campo, a exemplo do observado por Dieleman et al. (1995). Quando o modelo de Cousens (1985) é baseado exclusivamente na densidade de plantas daninhas, é comum superestimar esse parâmetro, inclusive ocorrendo valores superiores a 100\% (Jasieniuck et al., 1999; Massinga et al., 2001). De forma similar ao verificado com os demais parâmetros do modelo, o parâmetro c não diferiu entre ambientes. Como esse parâmetro representa um indicativo de competitividade da cultura, poder-se-ia apontar que a soja semeada em diferentes épocas pós-dessecação da cobertura vegetal não diferiu em habilidade competitiva. Porém, no

Tabela 1. Rendimento de grãos de soja na ausência de plantas daninhas e valores estimados dos parâmetros do modelo de regressão da hipérbole em razão da presença de picão-preto e guanxuma, em Passo Fundo, RS, 1998/1999 (ambiente 1) e Eldorado do Sul, RS, 1999/2000 (ambiente $2)^{(1)}$.

\begin{tabular}{|c|c|c|c|c|}
\hline \multirow[t]{2}{*}{ Ambiente } & \multirow{2}{*}{$\begin{array}{l}\text { Grãos } \\
\text { (kg/ha) }\end{array}$} & \multicolumn{3}{|c|}{ Parâmetros estimados ${ }^{(2)}$} \\
\hline & & $\begin{array}{c}\mathrm{i} \\
(\%)\end{array}$ & $\begin{array}{c}\mathrm{a} \\
(\%)\end{array}$ & $\begin{array}{c}\mathrm{c} \\
(\%)\end{array}$ \\
\hline $\begin{array}{l}1 \\
2\end{array}$ & $\begin{array}{l}2.362(138,81) \\
3.153(91,46)\end{array}$ & $\begin{array}{l}0,243^{\text {ns }}(0,11) \\
0,802(0,27)\end{array}$ & $\begin{array}{c}\text { Picão-preto }^{(3)} \\
44,05^{\text {ns }}(6,96) \\
46,83(5,20)\end{array}$ & $\begin{array}{l}0,176^{\mathrm{ns}}(0,05) \\
0,211(0,04)\end{array}$ \\
\hline $\begin{array}{l}1 \\
2\end{array}$ & $\begin{array}{l}2.614(47,43) \\
2.491(78,74)\end{array}$ & $\begin{array}{l}0,401(0,22) \\
1,460(1,98)\end{array}$ & $\begin{array}{c}\text { Guanxuma }^{(4)} \\
25,90(11,43) \\
61,78(11,86)\end{array}$ & $\begin{array}{r}0,108(0,06) \\
-0,008(0,06)\end{array}$ \\
\hline
\end{tabular}

(1) Valores entre parênteses indicam o erro-padrão assintótico dos parâmetros. ${ }^{(2)}$ i: porcentagem de perda de rendimento por unidade de planta daninha quando sua densidade se aproxima de zero; a: porcentagem de perda de rendimento quando a densidade de plantas daninhas tende ao infinito; c: parâmetro próprio do modelo. ${ }^{(3)}$ Comparação entre ambientes significativo a $5 \%$ de probabilidade. ${ }^{(4)}$ Comparações entre ambientes e entre parâmetros não realizadas. ${ }^{n s}$ Valores de parâmetros comparados entre ambientes não diferem entre si a 5\% de probabilidade. 
ambiente 1, a inclusão de uma planta de picão causou perdas de rendimento de $0,48 \%, 1,07 \%$ e $2,64 \%$, e no ambiente 2 , de $0,97 \%, 5,08 \%$ e $9,37 \%$ nas semeaduras realizadas 3, 7 e 11 DAD. Portanto, é provável que a semeadura realizada próximo à dessecação não só aumentasse a vantagem competitiva da soja em relação à planta daninha como também conferisse maior tolerância da planta daninha ao aumento em sua densidade, como verificado por Rizzardi (2002).

Nos experimentos com guanxuma, em razão de diferenças acentuadas ocorridas nas épocas de semeadura da soja entre os ambientes para experimentos, optou-se em não se realizar comparação estatística quanto aos ambientes e parâmetros do modelo. No ambiente 1, o segundo modelo de Cousens et al. (1987) apresentou limitada capacidade previsiva, com coeficiente de determinação muito baixo $\left(\mathrm{R}^{2}=0,29\right)$, embora estatisticamente significativo (Figura 2). As perdas de rendimento causadas pelas plantas daninhas nesse ambiente foram mais baixas, na maioria dos casos inferiores a $20 \%$. O menor efeito causado por guanxuma à soja pode atribuir-se tanto à menor habilidade competitiva intrínseca da planta daninha quanto ao efeito supressor da soja, o que afetou o desenvolvimento da planta daninha, causando até mesmo morte de plantas.

No ambiente 2, o ajuste do modelo aos dados de perdas de rendimento causadas pela presença de guanxuma foi satisfatório (Figura 2). Nesse ambiente, como a semeadura da soja foi realizada apenas 20 a 28 dias após aplicação de dessecante à cobertura vegetal, em muitas situações as reduções no rendimento ocasionadas por guanxuma posicionaram-se entre $30 \%$ e $40 \%$; portanto, superiores às observadas no ambiente 1 (Figura 2). Praticamente não ocorreram diferenças acentuadas nas perdas estimadas entre cada época de semeadura da soja, principalmente no ambiente 2 . No ambiente 1 , a inclusão de uma planta de guanxuma causou perdas de rendimento de $0,51 \%, 0,88 \%$ e $1,41 \%$, e no ambiente 2 , de $1,22 \%, 1,20 \%$ e $1,16 \%$, nas semeaduras realizadas 3 , 7 e 11 dias e 20, 24 e 28 DAD, respectivamente. Portanto, dentro de um mesmo ambiente, as diferenças nas épocas de semeadura da soja de até oito dias, em relação à dessecação da cobertura vegetal, não se traduziram em vantagem na habilidade competitiva da cultura. Assim, pode-se considerar que a época de emergência relativa guanxuma:soja é uma variável menos importante na determinação da interferência dessa planta daninha em soja do que o foi em
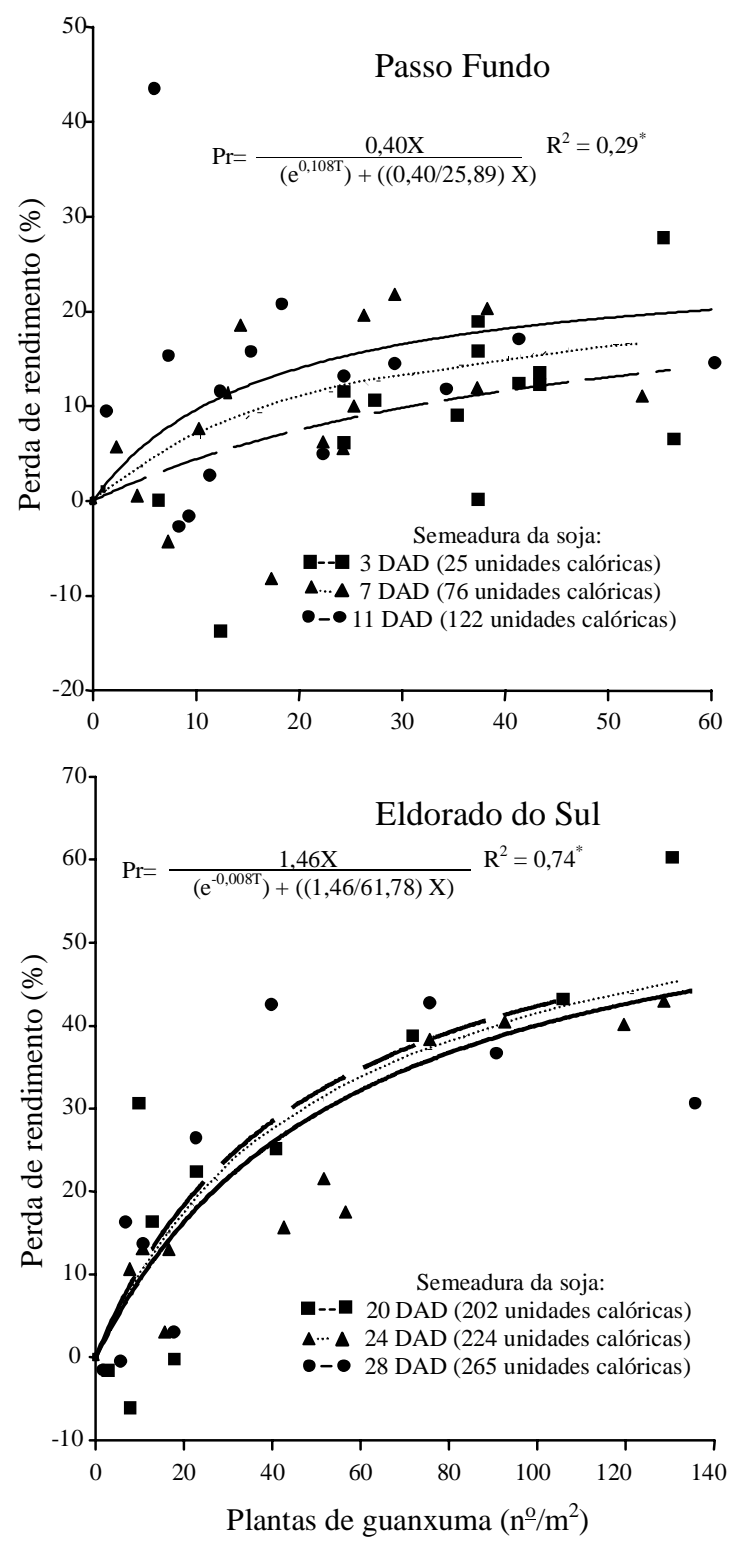

Figura 2. Perda de rendimento $\left(\mathrm{P}_{\mathrm{r}}\right)$ de grãos de soja em razão da densidade de plantas de guanxuma e da época de semeadura da soja após a dessecação (DAD: dias após dessecação) da cobertura vegetal, em Passo Fundo, RS, 1998/1999 e Eldorado do Sul, RS, 1999/2000. Nas equações de perdas de rendimento, $\mathrm{X}$ é a densidade de plantas daninhas; T é a época de semeadura. 
relação ao picão-preto. O comportamento observado com guanxuma associa-se, entre outros fatores, ao crescimento lento que essa espécie apresenta, o que permitiu à soja, mesmo sendo estabelecida mais tarde em relação à planta daninha, suprimir o seu desenvolvimento, pelo menos em parte, a exemplo do constatado por Rizzardi (2002).

Os parâmetros estimados pelo modelo de Cousens et al. (1987) com guanxuma indicam que, numericamente, as estimativas i e a foram 3,6 e 2,4 vezes maiores no ambiente 2 do que no ambiente 1 (Tabela 1 ). Esse fato ressalta o efeito causado pelo maior atraso na semeadura da cultura pós-dessecação em aumentar as perdas de rendimento no ambiente 2 . Em relação a esses parâmetros, na estimativa do parâmetro a, os erros-padrões foram praticamente iguais entre os ambientes; porém, quanto a estimativa i, eles diferiram bastante, sendo mais elevado no segundo ambiente. Esse elevado erro-padrão dificulta estimar com precisão perdas em densidades baixas, a exemplo do descrito anteriormente com picão-preto.

As estimativas do parâmetro c, com relação à guanxuma, apresentaram erros-padrões semelhantes entre ambientes; porém, os valores estimados mostraram-se divergentes, com valores positivo e negativo nos ambientes 1 e 2 , respectivamente (Tabela 1 ). Os valores negativos podem ser atribuídos à emergência muito antecipada das plantas daninhas em relação à cultura (Kropff et al., 1992). Segundo esses autores, numa situação assim, como o modelo de Cousens et al. (1987) incorpora as variáveis densidade e época de emergência e assume perda máxima de rendimento constante, independentemente da densidade de plantas daninhas, o coeficiente de época relativa de emergência das plantas daninhas torna-se negativo. Embora valores negativos de c não pareçam ser realistas, tal situação pode ocorrer em áreas de semeadura direta, em que o intervalo entre dessecação da cobertura vegetal e semeadura da cultura seja demasiadamente longo, o que permite o estabelecimento e desenvolvimento das plantas daninhas muito antes do que a cultura.

A validação dos modelos ajustados indicou pequena variação nos coeficientes de correlação (r), ao se compararem os valores preditos e os observados com picão-preto, os quais foram estatisticamente significativos $(\mathrm{p}<0,05)$ em ambos os ambientes (Tabela 2). No ambiente 1, apesar de o coeficiente de determinação ter sido 0,52 (Figura 1), houve ajuste razoável entre os valores preditos e os observados (Tabela 2). Em relação à guanxuma, nos dois ambientes houve significância estatística dos coeficientes de correlação ( $\mathrm{p}<0,05)$ (Tabela 2). No ambiente 1, o valor de $\mathrm{r}$ foi consideravelmente baixo $(0,32)$, o que pode decorrer da reduzida capacidade previsiva do modelo $\left(\mathrm{R}^{2}=0,29\right)$ (Figura 2). Porém, no ambiente 2 , o valor de $\mathrm{r}$ foi de 0,72 .

Uma análise conjunta dos resultados de validação (Tabela 2) revela que, de maneira geral, os modelos testados apresentaram capacidade previsiva satisfatória, diferentemente do que foi salientado por Webster et al. (2000) e Massinga et al. (2001). No entanto, é importante esclarecer que, mesmo se utilizando rendimentos de grãos de soja livre de plantas daninhas de experimentos vizinhos conduzidos na área experimental, para se calcular as perdas utilizadas na validação, o efeito das plantas daninhas foi mensurado em parcelas testemunhas contíguas aos experimentos; portanto, no mesmo ano de realização dos experimentos que propiciaram o ajuste do modelo. Esse procedimento pode, em parte, ter superestimado a capacidade previsiva do modelo.

Os resultados do presente trabalho mostram que o ajuste do modelo de Cousens et al. (1987), que acrescenta uma variável adicional, permitiu com relação à guanxuma, mas principalmente com picão-preto, ajustar e prever adequadamente as perdas de rendimento em diferentes épocas de estabelecimento da soja em relação à data de dessecação da cobertura vegetal. Apesar disso, ainda houve bastante variação embutida, que não foi explicada pelo modelo. Tal variação revela que há outros fatores, além da época

Tabela 2. Coeficientes de correlação linear simples entre perdas de rendimento de grãos de soja observadas e estimadas em razão das densidades de plantas de picão-preto e guanxuma, em Passo Fundo, RS, 1998/1999 e Eldorado do Sul, RS, 1999/2000.

\begin{tabular}{lcc}
\hline Ambiente & \multicolumn{2}{c}{ Coeficientes de correlação (r) } \\
\cline { 2 - 3 } & Picão-preto & Guanxuma \\
\hline Passo Fundo & $0,60^{*}$ & $0,32^{*}$ \\
Eldorado do Sul & $0,66^{*}$ & $0,72^{*}$ \\
\hline
\end{tabular}

${ }^{*}$ Valores significativos a $5 \%$ de probabilidade. 
relativa de emergência e da densidade das plantas daninhas, influenciando a perda de rendimento da soja.

\section{Conclusões}

1. O atraso na semeadura da soja em relação à data de dessecação da cobertura vegetal, no sistema de semeadura direta, aumenta as perdas de rendimento de grãos decorrentes da interferência de guanxuma e picão-preto.

2. Em um mesmo ambiente, o atraso na época de semeadura da soja em relação à dessecação da cobertura vegetal causa maiores reduções no rendimento de grãos quando a cultura sofre interferência de picão-preto do que de guanxuma.

3. O modelo da hipérbole retangular no qual são incluídos os efeitos da densidade de planta daninha e da época relativa de sua emergência é capaz de prever as perdas de rendimento da soja semeada em diferentes épocas em relação à dessecação da cobertura vegetal.

\section{Agradecimentos}

Ao CNPq (Proc. № 460789/00-7) e à Fapergs (Proc. № 00/0228.9), pelo apoio financeiro.

\section{Referências}

BOSNIC, A. C.; SWANTON, C. J. Economic decision rules for postemergence herbicide control of barnyardgrass (Echinochloa crus-galli) in corn (Zea mays). Weed Science, Lawrence, v. 45, n. 4, p. 557-563, 1997a.

BOSNIC, A. C.; SWANTON, C. J. Influence of barnyardgrass (Echinochloa crus-galli) time of emergence and density on corn (Zea mays). Weed Science, Lawrence, v. 45 , n. 2, p. 276-282, 1997 b.

CHIKOYE, D.; SWANTON, C. J. Evaluation of three empirical models depicting Ambrosia artemisiifolia competition in white bean. Weed Research, Oxford, v. 35, n. 5 , p. $421-428,1995$.

CHIKOYE, D.; WEISE, S. F.; SWANTON, C. J. Influence of common ragweed (Ambrosia artemisiifolia) time of emergence and density on white bean (Phaseolus vulgaris). Weed Science, Champaign, v. 43, n. 3, p. 375-380, 1995.
COUSENS, R. An empirical model relating crop yield to weed and crop density and a statistical comparison with other models. Journal of Agricultural Sciences, Cambridge, Inglaterra, v. 105, n. 3, p. 513-521, 1985.

COUSENS, R. D.; BRAIN, P.; O'DONOVAN, J. T.; O'SULLIVAN, P. A. The use biologically realistic equations to describe the effects of weed density and relative time of emergence on crop yield. Weed Science, Champaign, v. 35, n. 5, p. 720-725, 1987.

COUSENS, R. D.; MOKHTARI, S. Seasonal and site variability in the tolerance of wheat cultivars to interference from Lolium rigidum. Weed Research, Oxford, v. 38, n. 4, p. 301-307, 1998.

DIELEMAN, A.; HAMILL, A. S.; FOX, G. C.; SWANTON, C. J. Decision rules for postemergence control of pigweed (Amaranthus spp.) in soybean (Glycine max). Weed Science, Champaign, v. 44, n. 1, p. 126-132, 1996.

DIELEMAN, A.; HAMILL, A. S.; WEISE, S. F.; SWANTON, C. J. Empirical models of pigweed (Amaranthus spp.) interference in soybean (Glycine max). Weed Science, Champaign, v. 43, n. 4, p. 612-618, 1995.

EMBRAPA. Centro Nacional de Pesquisa de Solos (Rio de Janeiro, RJ). Sistema brasileiro de classificação de solos. Brasília: Embrapa-SPI/Embrapa-CNPS, 1999. 412 p.

FLECK, N. G.; RIZZARDI, M. A.; VIDAL, R. A.; MEROTTO JÚNIOR, A.; AGOSTINETTO, D.; BALBINOT JÚNIOR, A. A. Período crítico para controle de Brachiaria plantaginea em função de épocas de semeadura da soja após dessecação da cobertura vegetal. Planta Daninha, Viçosa, MG, v. 20, n. 1, p. 53-62, 2002.

FLOREZ, J. A.; FISCHER, A. J.; RAMIREZ, H.; DUQUE, M. C. Predicting rice yield losses caused by multispecies weed competition. Agronomy Journal, Madison, v. 91, n. 1, p. 87-92, 1999.

GOMEZ, K. A.; GOMEZ, A. A. Statistical procedures for agricultural research. 2nd ed. New York: J. Wiley, 1984. $680 \mathrm{p}$.

JASIENIUCK, M.; MAXWELL, B. D.; ANDERSON, R. L.; EVANS, J. O.; LYON, D. J.; MILLER, S. D.; MORISHITA, D. W.; OGG JUNIOR, A. G.; SEEFELDT, S.; STAHLMAN, P. W.; NORTHAM, F. E.; WESTRA, P.; KEBEDE, Z.; WICKS, G. A. Site-to-site and year-to-year variation in Triticum aestivum-Aegilops 
cylindrica interference relationships. Weed Science, Lawrence, v. 47, n. 5, p. 529-537, 1999.

KNEZEVIC, S. Z.; HORAK, M. J.; VANDERLIP, R. L. Relative time of redroot pigweed (Amaranthus retroflexus L.) emergence is critical in pigweed-sorghum [Sorghum bicolor (L.) Moench] competition. Weed Science, Lawrence, v. 45, n. 4, p. 502-508, 1997.

KNEZEVIC, S. Z.; WEISE, S. F.; SWANTIN, C. J. Comparison of empirical models depicting density of Amaranthus retroflexus L. and relative leaf area as predictors of yield loss in maize (Zea mays L.). Weed Research, Oxford, v. 35, n. 4, p. 207-214, 1995.

KROPFF, M. J.; SPITTERS, J. T. A simple model of crop loss by weed competition from early observations on relative leaf area of the weeds. Weed Research, Oxford, v. 31, n. 2, p. 97-105, 1991.

KROPFF, M. J.; WEAVER, S. E.; SMITS, M. A. Use of ecophysiological models for crop-weed interference: relations amongst weed density, relative time of weed emergence, relative leaf area, and yield loss. Weed Science, Champaign, v. 40, n. 2, p. 296-301, 1992.

MASSINGA, R. A.; CURRIE, R. S.; HORAK, M. J.; BOYER JUNIOR, J. Interference of palmer amaranth in corn. Weed Science, Lawrence, v. 49, n. 2, p. 202-208, 2001.

MORTENSEN, D. A.; BASTIAANS, L.; SATTIN, M. The role of ecology in the development of weed management systems: an outlook. Weed Research, Oxford, v. 40, n. 1, p. 49-62, 2000.

MULUGETA, D.; BOERBOOM, C. M. Critical time of weed removal in glyphosate-resistant Glycine max. Weed Science, Lawrence, v. 48, n. 1, p. 35-42, 2000.

RIZZARDI, M. A. Nível de dano econômico para tomada de decisão no controle de picão-preto (Bidens spp.) e guanxuma (Sida rhombifolia L.) na cultura da soja. 2002. $177 \mathrm{f}$. Tese (Doutorado em Fitotecnia) - Universidade Federal do Rio Grande do Sul, Porto Alegre, 2002.

SAS INSTITUTE (Cary, Estados Unidos). Statistical analysis system: user's guide: version 6. 4th ed. Cary, 1989. $846 \mathrm{p}$.

WEBSTER, T. M.; CARDINA, J.; WOODS, S. J. Apocynum cannabinum interference in no-till Glycine max. Weed Science, Lawrence, v. 48, n. 6, p. 716-719, 2000.

WIESE, A. M.; BINNING, L. K. Calculation the threshold temperature of development for weeds. Weed Science, Champaign, v. 35, n. 2, p. 177-179, 1987. 